\title{
Explaining First-Year Seedling Survival from Quality Distributions of Bare-Root Seedlings and Microsites in Industrial Plantations
}

\author{
Puskar N. Khanal ${ }^{1 *}$, Thomas J. Dean ${ }^{2}$, Scott D. Roberts ${ }^{3}$, Donald L. Grebner ${ }^{3}$, Thomas J. Straka ${ }^{1}$ \\ ${ }^{1}$ Department of Forestry and Environmental Conservation, Clemson University, Clemson, SC, USA \\ ${ }^{2}$ School of Renewable Natural Resources, Louisiana State University Agricultural Center, Baton Rouge, LA, USA \\ ${ }^{3}$ Department of Forestry, Mississippi State University, Starkville, MS, USA \\ Email: *pkhanal@clemson.edu
}

How to cite this paper: Khanal, P. N., Dean, T. J., Roberts, S. D., Grebner, D. L., \& Straka, T. J. (2018). Explaining First-Year Seedling Survival from Quality Distributions of Bare-Root Seedlings and Microsites in Industrial Plantations. Open Journal of Forestry, 8, 362-379.

https://doi.org/10.4236/ojf.2018.83023

Received: May 2, 2018

Accepted: July 21, 2018

Published: July 24, 2018

Copyright $\odot 2018$ by authors and Scientific Research Publishing Inc. This work is licensed under the Creative Commons Attribution International License (CC BY 4.0).

http://creativecommons.org/licenses/by/4.0/ (c) (i) Open Access

\begin{abstract}
First-year seedling survival impacts all subsequent management planning in plantation forestry. Descriptive statistics of first-year seedling survival data from the Louisiana Department of Agriculture and Forestry (LDAF) indicated that survival success reaches a plateau at between $79 \%-85 \%$ under normal weather conditions. We provide an explanation for this plateau based on an analysis of seedling and microsite qualities involved in operational pine plantations by: 1) using a conceptual model demonstrating how variation in seedling quality and microsite quality interact to determine plantation survival, 2) presenting an example to characterize quality distributions of seedling and microsite qualities, and 3) comparing model outcomes based on measured distributions to realistic values of first-year survival. Simulation results indicated that consistent survival could result from random pairings of initial seedling and site quality distributions. LDAF data analysis indicated that $72 \%$ of seedlings were associated with the most frequent quality class that comprised seedlings with stem caliper between 3.2 to $4.7 \mathrm{~mm}$ and average stem height and volume of $25.75 \mathrm{~cm}$ and $3.43 \mathrm{~cm}^{3}$, respectively. Similarly, assessment of microsites at planting sites in Southeast Louisiana indicated that $48 \%$ of planted seedlings were associated with the most frequent microsite quality class which supported first-year height increment between 9 to $29 \mathrm{~cm}$. Modelling of current operational practice indicated that using seedlings with larger caliper size would increase first year survival, but would result in higher establishment costs. The conceptual model could be modified to for use in other regions regardless of species types involved.
\end{abstract}

\section{Keywords}

Seedling Survival, Site Quality, Microsite, Simulation 


\section{Introduction}

First-year seedling survival is a critical element in plantation forestry since all subsequent management planning depends on the quality of stand establishment. Efforts to achieve good seedling establishment can also be the most expensive aspect of a silvicultural regime because high establishment costs are carried through the entire rotation. Therefore, the use of high quality seedlings planted on favorable microsites is desirable for ensuring first-year survival success.

Seedling quality is characterized as the ability of the seedling to quickly become established and initiate growth. Nursery techniques often involve standardized protocols and subsequent grading to supply quality seedlings that give the best chance of survival and subsequent growth (Feret \& Kreh, 1985). Microsite quality refers to the site conditions into which the individual seedling is planted, and how favorable they are to seedling survival and growth (Puttonen, 1989).

A primary goal of site preparation is to create microsites that allow seedlings to realize their growth potential (Dougherty \& Gresham, 1988). Since the 1950s, mechanical site preparation techniques have become standard practice in the southern US (Fox et al., 2007a); practices such as disking, bedding, and subsoiling alter soil properties so as to affect seedling rootability, water storage, nutrient content and supply, and competing vegetation (Morris et al., 2006). Similarly, the uses of herbicides, and to some extent prescribed fire, influences seedling competition (Amishev \& Fox, 2006; Fox et al., 2007b; Harrington et al., 1998).

Various factors define seedling quality relative to plantation establishment. Morphological and physiological parameters such as stem caliper, height, root-shoot ratio, water potential, root regeneration potential, and photosynthetic efficiency have been shown as major indicators of seedling quality (Brønnum, 2005; Larsen et al., 1986; South et al., 2001a; Thompson, 1985). Seedling caliper and height are most frequently used for seedling grading because of the ease of measurement, as well as their positive relationship to seedling survival. Similarly, numerous physical and chemical properties have been used to characterize microsite quality. In the US South, the most frequently cited site factors affecting seedling survival and growth include mechanical resistance (Lincoln et al., 2007), water potential and moisture availability (Fox et al., 2007b; Morris et al., 2006), and the soil nutrient status (Margolis \& Brand, 1990). Site preparation techniques used to ameliorate these factors include bedding and fertilization treatments which, along with competition control, alter microsites to either increase soil resource availability or enhance the ability of seedlings to garner those resources (Lincoln et al., 2007).

Nursery and site preparation practices have improved over time, resulting in increased overall seedling and site quality respectively (Boyer \& South, 1984). Current tree improvement efforts are working towards genetically improved seedlings suited for specific growth environments which could further improve seedling performance allowing them to achieve their genetic potential (Fox et al., 
2007a). However, there remains a significant difference in survival rates between seedlings in research plantings and those in operational settings.

First-year seedling survival in operational plantings has remained on a plateau of between $80 \%$ - $90 \%$, while in research settings survival is commonly greater than 90\% (South et al., 2001b). Hitch et al. (1996) found an 8\% difference in first-year survival of loblolly pine seedlings between experimental and operational plantations. Annual seedling survival reported by the Louisiana Department of Agriculture and Forestry (1997-2007) showed that first year survival of bare-root loblolly pine seedlings in industrial plantations averaged $82 \%$ for the period 1997 to 2007 excluding 1998 and 2006 (Figure 1). These two years had exceptionally severe weather conditions resulting in considerably lower than average survival. In 2008, U.S. experienced near normal climate condition with average temperature of $11.7^{\circ} \mathrm{C}$ and precipitation of $774 \mathrm{~mm}$, both values were slightly above the $20^{\text {th }}$ century average (NOAA, 2008).

The reason for the plateau in current first-year seedling survival could be due to standardized nursery and seedling handling practices, as well as the site preparation techniques. In the southern U.S., most pine seedling nursery operating techniques, grading systems, and seedling handling procedures have been standardized to supply uniform and quality seedlings (Fox et al., 2007a). Similarly, site preparation and vegetation control have become standard practices in coastal plain plantations (Harrington et al., 1998; Jokela et al., 2004; Fox et al., 2007a). These standardized practices may be resulting in an underlying quality distribution of both seedlings and microsites. Plantation survival then could be considered the result of random pairing of the two distributions of seedling and microsite quality. While considerable work has been aimed at understanding the factors affecting seedling survival (Davis \& Jacobs, 2005; Feret \& Kreh, 1985; Folk \& Grossnickle, 1997; Schultz, 1999), none of the earlier studies have attempted to explain the survival plateau as being dependent on the initial seedling and microsite quality distribution in current plantation practices.

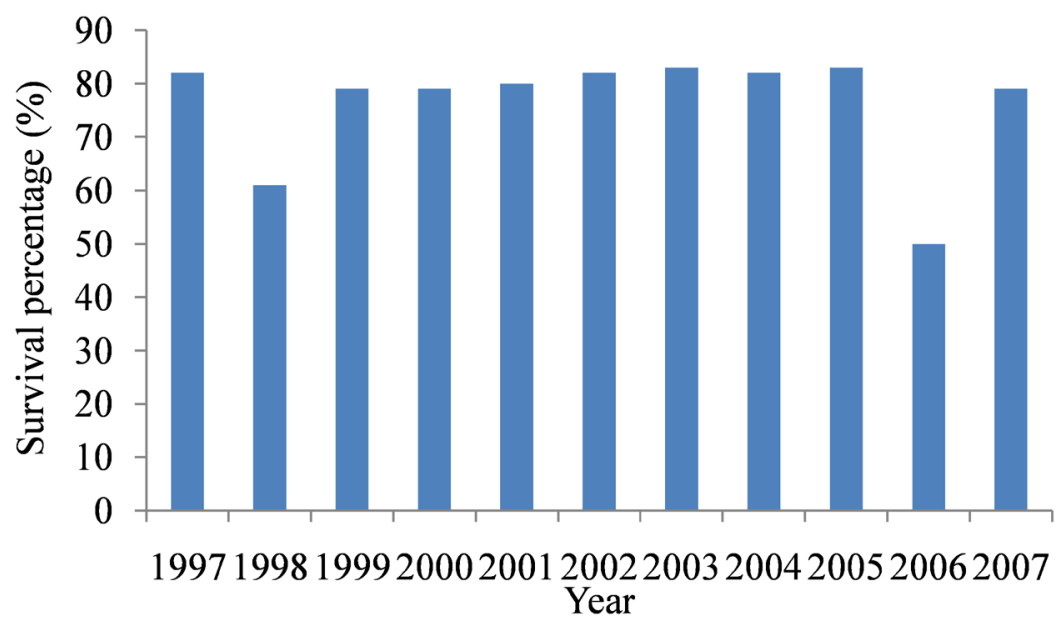

Figure 1. First-year pine seedling survival in Louisiana from 1997 to 2007 (Louisiana Department of Agriculture and Forestry 1997-2007). 
We propose a conceptual model that explains plantation seedling survival as the result of the random pairing of seedlings and microsites. This model suggests that the quality distributions of seedlings and microsites are responsible for the observed plateau in seedling survival in loblolly pine plantations. The specific objectives are: 1) to present a conceptual model demonstrating how variation in seedling and microsite quality interact to determine plantation survival, 2) to present an initial attempt to characterize quality distributions of seedling and microsite qualities, and 3) to compare model outcomes based on measured distributions to realistic values of first-year survival.

\section{The Conceptual Model}

Mathematically, the model consists of two components-the joint frequency distribution of the seedling and microsite quality, and a function for predicting the probability of first year survival using the joint frequency distribution. The sum of predicted probabilities from the joint distribution is the overall seedling survival for the plantation.

The model can also be described in discrete terms using quality classes. The effect of various distributions of quality classes on seedling survival is relatively easy to illustrate. To illustrate the discrete version of the model, we assumed five seedling quality classes, S1 - S5. We chose five quality classes because the current literature regarding seedling quality often discriminates seedlings into advanced quality, high quality, average, poor, and very poor classes. South et al. (1985) divided seedling quality into five quality classes: morphologically advanced, grade 1 , grade 2, grade 3, and cull class. Similarly, microsites were divided into five classes M1 - M5. For both seedlings and microsites, 1 indicates the highest quality while 5 indicates the poorest quality. Relative frequency values were arbitrarily assigned to the five seedlings and microsite quality classes to create a distribution of each (Table 1).

To simulate a planting of the assumed quality distributions in Table 1, we conducted a repeated random pairing of each seedling and microsite quality by multiplying the relative frequencies of the two respective distributions. The repeated random pairing implies each seedling gets paired with each microsite, and vice-versa. The pairing generated a 5 by 5 pairing matrix (Table 2). To assess

Table 1. Seedling (S) and Microsite (M) quality distribution for the conceptual model, where quality class 5 indicates lowest value and quality class 1 indicates the best value.

\begin{tabular}{ccc}
\hline \multirow{2}{*}{ Quality class } & \multicolumn{2}{c}{ Relative frequency } \\
\cline { 2 - 3 } & Seedling (S) & Microsite (M) \\
\hline 2 & 0.10 & 0.20 \\
3 & 0.25 & 0.20 \\
4 & 0.35 & 0.35 \\
5 & 0.20 & 0.15 \\
& 0.10 & 0.10 \\
\hline
\end{tabular}


Table 2. Joint frequency distribution of seedling $(\mathrm{S})$ and microsite $(\mathrm{M})$ quality for the conceptual model, where quality class 5 indicates lowest value and quality class 1 indicates the best value. The cell values in each seedling and microsite quality pairing indicate relative frequencies.

\begin{tabular}{cccccc}
\hline \multirow{2}{*}{$\begin{array}{c}\text { Microsite } \\
\text { quality }\end{array}$} & \multicolumn{5}{c}{ Seedling quality } \\
\cline { 2 - 6 } & S1 & S2 & S3 & S4 & S5 \\
\hline M1 & 0.02 & 0.05 & 0.07 & 0.04 & 0.02 \\
M2 & 0.02 & 0.05 & 0.07 & 0.04 & 0.02 \\
M3 & 0.03 & 0.08 & 0.12 & 0.07 & 0.03 \\
M4 & 0.01 & 0.03 & 0.05 & 0.03 & 0.01 \\
M5 & 0.01 & 0.02 & 0.03 & 0.02 & 0.01 \\
\hline
\end{tabular}

survival for each pairing in simple terms of yes or no, we assigned probability of survival 1 or 0 (Table 3 ) to each combination of seedling and microsite qualities in Table 2. This means that some pairs will observe no mortality while the remaining pairs will have no survival after one year. The reason for using extreme values of 1 or 0 is to exhibit the model in its most simplified form.

The central assumption is that higher quality seedling and microsite pairs will observe no mortality, i.e. $1 \%$ or $100 \%$ probability of survival, while poor quality pairing will have no survival, i.e. $0 \%$ probability of survival. In reality, the probability of survival may approach 1 for a high quality seedling planted on a high quality microsite, to nearly 0 for a poor quality seedling planted on a poor microsite. In fact, the probabilities may never truly reach 1 or 0 . A great seedling on a great microsite might still die due to poor handling or planting of the seedling, poor growing conditions after planting, or random probability of damage from a variety of sources. Similarly, a bad seedling on a bad site has a small chance of survival due to favorable environmental conditions (e.g. rain or temperature) following planting.

The proportion of the seedling population surviving in each pairing is computed by multiplying, element by element, the relative frequency of the pairings in Table 2 by the survival probability assumptions in Table 3. For this example, the result is shown in Table 4. Summing of the values across cells yields the final survival percentage of this hypothetical simulation. In this example, the survival was $52.5 \%$ after one growing season (Table 4). This simulation model highlights the importance of the random pairing of initial seedling and site quality distributions to determine final survival.

\section{The Simulation Model}

In the conceptual model, we outlined a very simplistic model involving a seedling and site quality distribution and computed its final survival result. In order to infer the initial quality distribution and final survival, we need to replicate the conceptual model for other seedling and site quality distributions with more realistic survival assumptions and compare the final survival results. To do this, we 
Table 3. Expected survival assumption for the conceptual model, where quality class 5 indicates the lowest value and quality class 1 the best value. Cell value 0 indicates no survival, while cell value 1 indicates $100 \%$ survival in a pairing of site quality and microsite quality.

\begin{tabular}{cccccc}
\hline \multirow{2}{*}{$\begin{array}{c}\text { Microsite } \\
\text { quality }\end{array}$} & S1 & S2 & S3 & S4 & S5 \\
\cline { 2 - 6 } M1 & 1 & 1 & 1 & 0 & 0 \\
M2 & 1 & 1 & 1 & 0 & 0 \\
M3 & 1 & 1 & 1 & 0 & 0 \\
M4 & 0 & 0 & 0 & 0 & 0 \\
M5 & 0 & 0 & 0 & 0 & 0 \\
\hline
\end{tabular}

Table 4. Predicted first-year survival for the conceptual model where quality class 5 indicates lowest value and quality class 1 indicates the best value. Cell values in each seedling and microsite quality pairing indicates relative frequencies.

\begin{tabular}{cccccc}
\hline \multirow{2}{*}{$\begin{array}{c}\text { Microsite } \\
\text { quality }\end{array}$} & S1 & S2 & S3 & S4 & S5 \\
\cline { 2 - 6 } M1 & 0.02 & 0.05 & 0.07 & 0 & 0 \\
M2 & 0.02 & 0.05 & 0.07 & 0 & 0 \\
M3 & 0.03 & 0.08 & 0.12 & 0 & 0 \\
M4 & 0 & 0 & 0 & 0 & 0 \\
M5 & 0 & 0 & 0 & 0 & 0 \\
\hline
\end{tabular}

created 20 different distributions for seedling quality and 20 distributions of microsite quality, each with five quality classes as in the conceptual model. The first ten seedling quality and microsite quality distributions included a varied proportion of lower quality seedlings and microsites in their respective quality classes S4, S5 and M4, M5, while the remaining 10 seedling and microsite distributions lacked any distribution in very poor quality classes S5 and M5. The relative frequency distribution pattern between quality classes indicated a shift from a few to no seedlings and microsites in lowest quality classes.

We followed the same simulation steps described in the conceptual model to determine final survival in each of these distributions. The pairing of 20 hypothetical seedling quality distributions and 20 microsite quality distributions resulted in 400 simulated plantings. We arbitrarily assumed a survival probability function that was different than the one used in our explanation of the conceptual model. Here we assume that even high quality pairings will observe some mortality and resulting in $95 \%$ survival and poor quality pairings will have an assumed $60 \%$ survival as opposed to the zero probability of survival in the conceptual model.

Element by element multiplication of each pairing with its corresponding assumed probability of survival, and then summing the resulting values provided 
the overall plantation survival of these 400 pairings after one growing season. The results indicate that the overall survival of these 400 simulated plantings varied between $49 \%$ and $99 \%$. Distributions with higher proportions of seedlings and microsites in S1 and S2 (M1 and M2) classes naturally resulted in higher survival percentages. This demonstrates how overall survival is responsive to the relative frequency distributions between initial seedling and microsite quality classes. These pairings created a survival distribution tending toward the higher end. However, frequency distribution with relatively higher proportions of seedlings and microsites in poor quality classes S4 and S5 (M4 and M5) resulted in final survival fairly insensitive to any changes in the distribution because most of those pairings in lower quality classes were assumed to fail. In other words, there was relatively small change in final survival from the alteration in initial frequency distributions involved in lower quality classes as compared to similar changes in higher quality classes of seedlings and microsites under similar survival probability assumption.

Additionally, the increase in frequency of seedlings and microsites in poor quality classes created distribution tending toward the lower end. These simulation results demonstrate how final survival is dependent on the initial quality distributions and how consistent survival could result from the random pairing of similar seedling and microsite quality distributions. This also provides initial support for the concept that our nursery and site preparation practices might be providing consistently similar quality distributions of seedlings and microsites thus resulting in the observed plateau in first year seedling survival.

\section{The Case Study}

A case study was used to quantify actual quality distributions of seedlings and microsites and randomly combine these pairings to determine how sensitive survival may be to random combinations of the relative frequency of seedling and microsite qualities. The ideal approach for this type of study would be to plant seedlings of known quality at microsites of known quality and measure first-year survival and growth. This could theoretically be accomplished by either planting commercially available seedlings on uniform microsites to measure seedling variation, or by planting clones on operationally prepared tract to measure microsite variation. However, because of the lack of access to seedlings and microsites prior to planting, a modified approach was followed, and therefore the results in this section were still hypothetical.

\subsection{Seedling and Microsite Measurements}

Seedlings and microsites commonly used in operational plantations were used to estimate their quality distributions. Seedling data were obtained using a 1000-seedling bag of bare root loblolly pine (Pinus taeda) seedlings, most commonly planted and intensively managed commercial pine species in the southern U.S., purchased from the Louisiana Department of Agriculture and Forestry 
(LDAF) in 2008. Stem caliper and height were measured on 907 unbroken seedlings. Seedling volume was calculated from the caliper and height measurements using the volume formula:

$$
V=\left[\pi d^{2} h\right] / 4
$$

where $V$ is stem volume, $d$ is stem diameter, and $h$ is shoot length. For the 907 seedlings, stem caliper, stem height, and volume averaged $4.05 \mathrm{~mm}, 25.12 \mathrm{~cm}$ and $3.43 \mathrm{~cm}^{3}$, respectively (Table 5). Stem caliper varied between 1.19 to 8.86 $\mathrm{mm}$, stem height between 13 to $39 \mathrm{~cm}$, and stem volume between 0.23 to 16.02 $\mathrm{cm}^{3}$. This clearly demonstrates that the nursery bag did not contain seedlings of uniform size.

Microsite data were collected from measurement of microsite variables at eight randomly selected recent plantations on Weyerhaeuser Inc. lands in Livingston Parrish, Louisiana. At each of these planting sites, 200 planted seedlings were randomly identified and their microsite environment assessed. Thus, a total 1600 seedlings and their microsites were assessed from the selected planting sites. The selected seedlings were assessed in spring 2008 and 2009 their first-year height increment was recorded.

To assess microsite, bed height and soil compaction were recorded at each seedling location. Soil penetration was measured using a pin penetrometer in four quadrants around each selected seedling. The penetrometer reading was an arbitrary scale ranging from 0 to 20 indicating the level of resistance. Bed height was measured using a level and a height pole. Measurements of bed height were taken from both sides of the bed where the seedling was planted. Soil samples were collected from every $10^{\text {th }}$ seedling microsite providing 160 samples from which to assess soil moisture content, texture, and mineral nitrogen content of the microsites.

A soil probe was used to collect soil from the rooting zone of the selected seedlings 15 to $25 \mathrm{~cm}$ below the soil surface. Mineral nitrogen content was assessed using approximate $10 \mathrm{gm}$ of soil from each sample extracted with $2 \mathrm{~N}$ KCL. The sample extracts were shaken at $220 \mathrm{rpm}$ for $1 \mathrm{hr}$. The extract was filtered after allowing it to settle for one hour. The filtrate was analyzed for total mineral nitrogen with an ammonia conductivity detector (Timberline Instrument Model 550 A). Soil moisture content was determined gravimetrically. Soil texture was determined using the hydrometric method as described in Klute (1986).

Table 5. Mean, minimum, and maximum for the caliper, stem height, and volume of the sampled 907 bare-root seedlings.

\begin{tabular}{cccc}
\hline Seedling variables & Mean & Minimum & Maximum \\
\hline Caliper $(\mathrm{mm})$ & 4.05 & 1.19 & 8.86 \\
Stem height $(\mathrm{cm})$ & 25.12 & 13.00 & 39.00 \\
Volume $\left(\mathrm{cm}^{3}\right)$ & 3.43 & 0.23 & 16.02 \\
\hline
\end{tabular}


Table 6 presents data collected from the measurement of 1600 selected seedlings and their associated microsite characteristics at the selected Weyerhaeuser Inc. sites in Louisiana. The average resistance index was 9.09, ranging from 1 to 20. Bed height averaged $26.37 \mathrm{~cm}$, varying between 4 and $50 \mathrm{~cm}$. The $160 \mathrm{sam}$ pled microsites displayed wide variation in mineral nitrogen content and texture. Soil nitrogen concentrations averaged $2.55 \mathrm{ppm}$, ranging between 0.20 and $10.56 \mathrm{ppm}$. In the surface horizon, the average proportion of sand, silt, and clay were $36.58 \%, 54.52 \%$ and $8.90 \%$, respectively-sand varied between $5.95 \%$ and $74.73 \%$, silt varied between $16.51 \%$ and $75.25 \%$, and clay varied between $5.34 \%$ and $21.26 \%$.

Interestingly, first-year height increment of the 1600 seedlings planted at these microsites varied between 0 to $87 \mathrm{~cm}$ with an average increment of $25.59 \mathrm{~cm}$. Seedling performance largely depends on the growing environment at the planting site (Dougherty \& Gresham, 1988; Jokela et al., 2004; Jose et al., 2003; Knapp et al., 2008; Puttonen, 1989), so the variation in measured microsite characteristics and the different height increments of the planted seedlings indicated that not all seedlings experienced the same microsite environment across the planting sites.

\subsection{Classifying Seedling and Microsite Quality}

Stem caliper of nursery seedlings was used as an indicator of seedling quality. South et al. (1985) provided seedling classification scheme based on stem caliper. Seedlings with larger stem caliper were in better quality class. To characterize the microsite quality distribution, predicted first-year height increment of seedlings based on microsite characteristics was used as a quality index.

The height increments were predicted from a reduced regression model with microsite variables (bed height, soil penetration, texture, and mineral nitrogen) as dependent variables against first-year height increment values. Thus, microsite quality was not based on actual seedling height increment, but rather on

Table 6. The mean, minimum, and maximum height increment of first-year loblolly pine seedlings and the associated microsite characteristics from measurements taken in spring 2008 and 2009.

\begin{tabular}{ccccc}
\hline Microsite variables & Number & Mean & Minimum & Maximum \\
\hline Height increment (cm) & 1600 & 25.59 & 0 & 87 \\
Soil penetration (no. unit) & 1600 & 9.09 & 1 & 20 \\
Bed height (cm) & 1600 & 26.37 & 4 & 50 \\
Soil moisture (\%) & 1600 & 21.65 & 1.21 & 10.56 \\
Total mineral nitrogen (ppm) & 160 & 2.55 & 0.20 & 74.43 \\
Sand (\%) & 160 & 36.58 & 5.95 & 75.25 \\
Silt (\%) & 160 & 54.52 & 16.51 & 21.26 \\
\hline
\end{tabular}


the modeled relationship between observed height increment and a suite of microsite variables. The reason for using predicted height increment instead of measured height was that empirical measurements of height increment are affected by both seedling and microsite quality, and thus confound the measure. Using predicted values isolates the influence of microsite factors on height increment.

The nursery seedlings were classified into quality classes based on their stem caliper. The seedlings were grouped into five quality classes and the relative frequency in each class was determined. This provided an estimated quality distribution for nursery seedlings in current operational plantations in Louisiana in which LDAF seedlings were used. Seedlings in quality class S5 had stem caliper less than $2.4 \mathrm{~mm}$, while stem caliper in quality class S1 were greater than $6.3 \mathrm{~mm}$ (Table 7). Seedlings in quality class S5 were smaller, and thus considered inferior. Their average stem height and volume were $19.88 \mathrm{~cm}$ and $0.65 \mathrm{~cm}^{3}$, respectively. Seedlings in class S1 had average stem height and volume $27.16 \mathrm{~cm}$ and $10.47 \mathrm{~cm}^{3}$, respectively.

These larger seedlings were presumed to be superior. There were $16 \%$ seedlings in S4 and S5 quality classes combined. The bale contained only $2 \%$ S5 quality seedlings and $10 \%$ S2 quality seedlings. Class S3 comprised $72 \%$ of the seedlings. This indicated that the bale contained mostly S3 class seedlings which could be the desired quality class, according to current standards.

To determine the microsite quality distribution, the range of predicted height increments was divided into five quality classes and the relative frequency in each class was computed. Microsites with less than zero predicted height increment were grouped into lowest quality class and the average height increment was required to be in the middle quality class M3. The M5 microsite quality class included sites with a predicted height increment of less than zero, while the M1 quality classes included sites with greater than $32 \mathrm{~cm}$ predicted first-year increment (Table 8). Other quality classes M4, M3, and M2 had predicted increments between 0 and $32 \mathrm{~cm}$ on first year. The microsite quality class M1 contained 33\% of the microsites and the lowest quality class M5 had 3\% of the microsites associated with it. The quality class M3 was the most frequent microsite with $48 \%$

Table 7. Seedling quality classes and the associated caliper range and relative frequency of the 907 bare-root seedlings. Seedling quality class 5 indicates lowest quality and class 1 indicates best quality.

\begin{tabular}{ccccc}
\hline $\begin{array}{c}\text { Seedling quality } \\
\text { class }\end{array}$ & $\begin{array}{c}\text { Caliper range } \\
(\mathrm{mm})\end{array}$ & $\begin{array}{c}\text { Relative } \\
\text { frequency }\end{array}$ & $\begin{array}{c}\text { Average height } \\
(\mathrm{cm})\end{array}$ & $\begin{array}{c}\text { Average volume } \\
\left(\mathrm{cm}^{3}\right)\end{array}$ \\
\hline S1 & $>6.3$ & 0.02 & 27.16 & 10.47 \\
S2 & $4.7-6.3$ & 0.10 & 26.51 & 5.69 \\
S3 & $3.2-4.7$ & 0.72 & 25.28 & 3.15 \\
S4 & $2.4-3.2$ & 0.15 & 23.08 & 1.52 \\
S5 & $<2.4$ & 0.01 & 19.88 & 0.65 \\
\hline
\end{tabular}


Table 8. Microsite quality class and associated predicted height increment and relative frequency of the first-year loblolly pine seedlings, with microsite quality class M5 indicating lowest quality and class M1 indicating best quality.

\begin{tabular}{ccc}
\hline Microsite Quality Class & Predicted height increment $(\mathrm{cm})$ & Relative frequency \\
\hline M1 & $>32$ & 0.33 \\
M2 & $29-32$ & 0.09 \\
M3 & $9-29$ & 0.48 \\
M4 & $0-9$ & 0.07 \\
M5 & $<0$ & 0.03 \\
\hline
\end{tabular}

of the microsites associated with it. This uneven relative frequency distribution between microsite quality classes highlights the heterogeneity in growing environment available to the new plantings.

Of the eight planting sites assessed, each site possessed a unique microsite quality distribution. The relative frequency between the quality classes characterized the overall suitability of the planting sites. Higher relative frequency in quality classes M1 and M2 comprised relatively better quality planting sites. The planting sites A, B, C and F were average quality planting sites with more than $50 \%$ of the microsites in $\mathrm{M} 3$ quality class. The site $\mathrm{H}$ had at least $60 \%$ microsites in the quality class M1 which suggests a relatively better quality planting site. This indicates that planting sites differ in terms of microsite quality distribution even though they may have received similar site preparation treatments.

\subsection{Comparing Model Outcomes to Realistic First-Year Survival Values}

The survival outcomes for every combination of seedlings and microsites were not measured for this part of the study; thus, the outcomes are still hypothetical. To develop the survival outcomes for every combination of seedlings and microsites, seedlings of known quality distribution must be planted on a site of a known microsite quality distribution which is left to a future study. Our predictions of first year survival from quality distributions of seedlings and microsites required assumptions about proportional survival of each seedling-microsite quality combination. The goal was to identify proportional survival assumptions that would approximate the actual average and range of seedling survival observed in Louisiana.

Different proportional survival scenarios were tested with an underlying presumption that higher quality pairings result in better survival than lower quality pairings. Three unique proportional survival scenarios assuming different survival rates for each quality combination were analyzed (Table 9). Tabulation of percentage survival rates for loblolly pine seedlings by South et al. (1985) was used a guide for assuming proportional survival rates for the three survival scenarios. 
Table 9. Proportional survival assumption for each pairing of seedling and microsite quality class under three different survival scenarios. Quality class 5 indicates lowest value and class 1 indicates best value. Cell value 0 indicates no survival, while 1 indicates $100 \%$ survival.

\begin{tabular}{|c|c|c|c|c|c|c|}
\hline \multirow[t]{2}{*}{ Scenarios } & \multirow{2}{*}{$\begin{array}{c}\text { Microsite } \\
\text { quality class }\end{array}$} & \multicolumn{5}{|c|}{ Seedling quality class } \\
\hline & & S1 & S2 & S3 & S4 & S5 \\
\hline \multicolumn{7}{|l|}{1 (Min) } \\
\hline & M1 & 0.77 & 0.77 & 0.74 & 0.71 & 0.67 \\
\hline & M2 & 0.77 & 0.76 & 0.71 & 0.68 & 0.62 \\
\hline & M3 & 0.74 & 0.71 & 0.66 & 0.65 & 0.57 \\
\hline & M4 & 0.71 & 0.68 & 0.65 & 0.64 & 0.48 \\
\hline & M5 & 0.67 & 0.62 & 0.57 & 0.48 & 0.32 \\
\hline \multicolumn{7}{|l|}{2 (Max) } \\
\hline & M1 & 1.00 & 0.98 & 0.97 & 0.95 & 0.91 \\
\hline & M2 & 0.98 & 0.96 & 0.96 & 0.94 & 0.87 \\
\hline & M3 & 0.97 & 0.96 & 0.96 & 0.91 & 0.81 \\
\hline & M4 & 0.95 & 0.94 & 0.91 & 0.86 & 0.71 \\
\hline & M5 & 0.91 & 0.87 & 0.81 & 0.71 & 0.55 \\
\hline \multicolumn{7}{|l|}{$3(\operatorname{Avg})$} \\
\hline & M1 & 0.89 & 0.88 & 0.86 & 0.83 & 0.79 \\
\hline & M2 & 0.88 & 0.86 & 0.84 & 0.81 & 0.75 \\
\hline & M3 & 0.86 & 0.84 & 0.81 & 0.78 & 0.69 \\
\hline & M4 & 0.83 & 0.81 & 0.78 & 0.75 & 0.60 \\
\hline & M5 & 0.79 & 0.75 & 0.69 & 0.60 & 0.44 \\
\hline
\end{tabular}

Minimum and maximum survival rates for each diameter class (South et al. 1985) were adopted as diagonal elements for the scenarios 1 (Min) and 2 (Max) matrix in Table 10. The proportional survival rates for the diagonal elements in scenario 1 (Min) ranged between 0.32 to 0.77 while the corresponding elements varied between 0.55 to 1.00 in case of the scenario 2 (Max). The diagonal elements for the survival scenario 3 (Avg) were average of the corresponding elements in scenarios 1 (Min) and 2 (Max). The diagonal elements varied from 0.44 to 0.89 for the scenario 3 (Avg). The non-diagonal values indicated an improvement in either seedling or microsite quality only, but not both. For the non-diagonal values, the proportional survival rate was an average of the nearest diagonal elements or cell values. These survival assumptions were obviously arbitrary. The rationale for using the different increases in survival probability was that we were attempting to generate a range in overall plantation survival estimates that matched observed survival rates reported by the LDAF.

Simulated plantings were performed to compare the mean and range of first-year survival under each of the three survival scenarios. The computation of 
Table 10. Predicted average, minimum, and maximum first-year survival percent from the pairing of seedling and microsites qualities at eight different planting sites under three different proportional survival scenarios. Cell values are first-year survival percentages for each scenario.

\begin{tabular}{cccc}
\hline & \multicolumn{3}{c}{ Survival scenario } \\
\cline { 2 - 4 } Survival (\%) & $\mathbf{1}$ (Min) & 2 (Max) & 3 (Avg) \\
\hline Average & 69 & 95 & 82 \\
Minimum & 66 & 93 & 79 \\
Maximum & 71 & 96 & 83 \\
\hline
\end{tabular}

expected plantation survival given the planting of LDAF nursery seedling quality distribution (Table 7) at each of the eight planting sites under each survival scenario (Table 9) predicted survival for each of the eight planting sites. The mean and range of final survival across the eight sites varied among the survival scenarios (Table 10).

Under scenario 1 (Min), average survival was $69 \%$, varying from $66 \%$ to $71 \%$. Average survival in scenario 2 ( $\mathrm{Max}$ ) was $95 \%$ and ranged from $93 \%$ to $96 \%$. Average survival in scenario 3 (Avg) was $82 \%$, varying from $79 \%$ to $83 \%$. The mean and range of first-year survival for the scenario 1 (Min) and 2 (Max) did not match the survival values reported by LDAF for Louisiana. In scenario 1 (Min), the average and range were relatively lower than reported values, and in scenario 2 (Max), the average and rage were higher than the reported LDAF survival results. Scenario 3 (Max) provided a better approximation of the first-year seedling survival reported in the LDAF data.

The survival range was wide enough to include the observed survival values and the average was relatively similar to the observed average. This survival assumption better approximated current operational survival rates in Louisiana. It implies that operational plantation practices in Louisiana might observe similar sensitivity related to first-year survival under given quality class pairings of seedlings and microsites. This scenario was selected for making further inferences on strategies to improve the survival plateau. However, we arbitrarily developed this survival probability matrix to try and match the LDAF reported survival rates; and there could be other survival probability matrices that might match the values. But, it is the closest approximation that could be made based on currently available empirical results providing survival rates for first-year loblolly pine seedlings.

The initial seedling and microsite quality distributions were the inputs for the proportional survival assumption for each pairing. Given the initial quality distributions in an operational environment, annual variations in weather conditions would be expected to result in variation around the average survival rate. The survival response to such annual variation would, however, largely depend on initial seedling and microsite quality. The lower quality pairings of seedlings and microsites would likely be more sensitive to such variation than high quality 
pairings.

Thus, the proportional survival of lower quality seedling and microsite pairings might be relatively higher under favorable weather condition but could be unreliable under more adverse conditions. In reality, the survival scenario assumption is an approximation rather than a field-based measurement because we never actually get to observe such proportion because of the existing divergence in definition of the term quality. However, the use of higher quality seedling and improved site preparation would certainly be expected to improve proportional survival. In essence, the initial quality distributions largely determine the underlying proportional survival decision matrix scenarios and ultimately the average survival.

\section{Implications for Current Practices}

Scenarios that increase plantation survival rates were identified and would indicate management actions that should lead to better meeting plant establishment objectives. The presence of lower quality seedlings and microsites appears to be largest contributor to a lower overall survival rate, as seen in scenario 3 (Avg). The inferior seedling/microsite pairing could be avoided by culling poor quality seedlings and avoiding poor microsites (that are identified before or during planting operations).

A simulated scenario included the removal of cull seedlings and adverse microsites. Obviously, the number of usable seedlings in the nursery bale decreased with the increase in minimum size of acceptable seedlings. Avoiding S5 quality seedlings during planting reduced the total number of seedlings available for planting to lower than 907. Similarly, with a strategy to avoid M5 quality microsites during planting, the number of usable microsites was less than 200, because the microsites supporting no predicted height were avoided during planting.

Simulation of the pairing of new seedling quality distribution with new microsite quality distribution was evaluated for the decision matrix scenario 3 (Avg). Elimination of S5 quality seedlings and avoiding the lowest quality microsites M5 during planting increased the average survival to over 90\%. Implementation of this scenario, however, would not be so simple and straightforward during actual planting operations. While determining seedling quality might be relatively straightforward, identifying and avoiding poor microsites during planting would be difficult and time-consuming. Some sort of sampling process might be required to precisely identify such sites, rather than relying on planting crews to avoid such sites during planting operations. More intensive site preparation practices at a higher cost could eliminate lower quality microsites, but could also alter some soil characteristics important for early height increment of the new seedlings. Thus, the option of avoiding lower quality microsites is not easily implemented.

A more practical option to enhance survival would be to increase the target seedling size in planting operations. Simulating the pairing of the new seedling 
distribution after culling inferior seedlings with the original microsite distribution increased the average survival. Eliminating seedlings of less than 3, 5, and 6 $\mathrm{mm}$ caliper from the nursery supply increased the average survival to $83 \%$ (range $80 \%$ to $84 \%$ ), $85 \%$ (range $83 \%$ to $87 \%$ ), and $86 \%$ (range $83 \%$ to $88 \%$ ), respectively. Similar results have been reported in earlier nursery trial studies (Radoglou \& Raftoyannis, 2002; South et al., 2001b). There is a tradeoff. Larger caliper seedlings should significantly increase average plantation survival and could raise the plateau in first-year seedling survival, but would also decrease the percentage of usable seedlings from the nursery supply and increase per seedling costs.

In practice, it would require the nursery to reduce seedling density in their beds, resulting in a higher production cost per seedling. Or, another option could be to discard smaller seedlings during planting. Our case study showed that eliminating seedlings 3,4 , or $5 \mathrm{~mm}$ caliper or smaller culled $10 \%, 51 \%$, and $89 \%$ of the seedlings, respectively. This increased the per seedling cost from $\$ 0.040$ to $\$ 0.048, \$ 0.087$, and $\$ 0.435$, respectively. These results indicate that increasing caliper size could be a promising strategy to increase first-year survival but at higher establishment cost.

Pine plantations in the southern US are the most intensively managed forests in the world, and this study used seedling and microsite data from the operational plantations in this region. The results of this study could easily be applied to other world regions and species types. The conceptual model, based on a probability distribution to analyze plantation success in an operational environment, could be modified for other designs of nursery and site preparation interactions. It is a new framework for future research into plantation survival dynamics.

These results particular apply to restoration efforts. The interaction of microsite and various planting stock factors (like stocktype and container type) in influencing plantation survival is well-established in the literature (Paterson, 1997, Pinto et al., 2011), but little attention has been focused on the seedling quality distribution, much less it's interaction with microsite, as one of these factors (Grossnickle and MacDonald 2018). Any factor influencing plantation survival can have significant impact on ecosystem restoration projects (Oliet \& Douglass, 2012). Thus, these results may prove valuable to managers and planners needing to modify plant establishment and management procedures to better meet restoration objectives (Harrington, 1999; Nunez-Mir et al., 2015).

\section{Conclusion}

This study highlights the combined influence of initial seedling quality and microsite quality on first-year seedling survival. Simulation results demonstrate that a consistent average survival rate could result from the repeated pairings of similar seedling and microsite quality distributions. Similarly, our case study results indicated that average first-year survival increased with the increase in seedling and microsite quality distribution. 
Recent attempts to use genetically improved seedlings, grading techniques, careful transportation and handling practices, and intensive site preparation practices could be viewed as attempts to use uniform and better quality seedlings and microsites in plantation establishment. Current practices could be considered somewhat standardized in terms of seedling production and site preparation techniques used in operational plantation management. But there remains considerable heterogeneity in seedling and microsite qualities. The availability of a significant proportion of lower quality seedlings and poor quality microsite could be a concern for increasing the first-year seedling survival.

These results suggest that first-year survival is responsive to initial quality distributions of seedlings and microsites, and the observed survival plateau could be the result of repeated pairing of similar quality distributions. This could be the unintentional result of standardized nursery management and site preparation practices providing similar distributions of seedling and microsite quality in operational planting environments. One of the practical strategies to increase first-year seedling survival is to increase seedling size. Larger seedlings could increase survival and growth, and ultimately yield from plantations.

\section{Acknowledgements}

We thank Weyerhaeuser Company for allowing access to their plantation sites in Louisiana to measure seedlings and collect soil samples and Christopher Allen for his help with field work, and Dr. Q. V. Cao for his help with the analysis. This study was supported by Lucius W. Gilbert Foundation, School of Renewable Natural Resources, Louisiana State University and the National Institute of Food and Agriculture, McIntire Stennis Project under LAB84307. Published with the approval of the Director of the Louisiana Agricultural Experiment Station as publication No. (pending).

\section{References}

Amishev, D. Y., \& Fox, T. R. (2006). The Effect of Weed Control and Fertilization on Survival and Growth of Four Pine Species in the Virginia Piedmont. Forest Ecology and Management, 236, 93-101. https://doi.org/10.1016/j.foreco.2006.08.339

Boyer, J. N., \& South, D. B. (1984). Forest Nursery Practices in the South.Southern Journal of Applied Forestry, 8, 67-75.

Brønnum, P. (2005). Preplanting Indicators of Survival and Growth of Desiccated Abies procera Bareroot Planting Stock. Scandinavian Journal of Forest Research, 20, 36-46. https://doi.org/10.1080/02827580510008257

Davis, A. S., \& Jacobs, D. F. (2005). Quantifying Root System Quality of Nursery Seedlings and Relationship to Outplanting Performance. New Forests, 30, 295-311. https://doi.org/10.1007/s11056-005-7480-y

Dougherty, P, M., \& Gresham, C. A. (1988). Conceptual Analysis of Southern Pine Plantation Establishment and Early Growth. Southern Journal of Applied Forestry, 12, $160-166$.

Feret, P. P., \& Kreh, R. E. (1985). Seedling Root Growth Potential as an Indicator of Loblolly Pine Field Performance. Forest Science, 31, 1005-1011. 
Folk, R. S., \& Grossnickle, S. C. (1997). Determining Field Performance Potential with the Use of Limiting Environmental Conditions. New Forests, 13, 121-138. https://doi.org/10.1023/A:1006514805052

Fox, T. R., Allen, H. L., Albaugh, T. J., Rubilar, R., \& Carlson, C. A. (2007b). Tree Nutrition and Forest Fertilization of Pine Plantations in the Southern United States. Southern Journal of Applied Forestry, 31, 5-11.

Fox, T. R., Jokela, E. J., \& Allen, H. L. (2007a). The Development of Pine Plantation Silviculture in the Southern United States. Journal of Forestry, 105, 337-347.

Grossnickle, S. C., \& MacDonald, J. E. (2018). Why Seedlings Grow: Influence of Plant Attributes. New Forests, 49, 1-34. https://doi.org/10.1007/s11056-017-9606-4

Harrington, C. A. (1999). Forests Planted for Ecosystem Restoration and Conservation. New Forests, 17, 175-190. https://doi.org/10.1023/A:1006539910527

Harrington, T. B., Minogue, P. J., Lauer, D. K., \& Ezell, A. W. (1998). Two Year Development of Southern Pine Seedlings and Associated Vegetation Following Spray-and-Burn Site Preparation with Imazapyr Alone or in Mixture with Other Herbicides. New Forests, 15, 89-106. https://doi.org/10.1023/A:1006567528659

Hitch, K. L., Shiver, B. D., \& Borders, B. E. (1996). Mortality Models for Newly Regenerated Loblolly Pine Plantations in the Georgia Piedmont. Southern Journal of Applied Forestry, 20, 197-202.

Jokela, E. J., Dougherty, P. M., \& Martin, T. A. (2004). Production Dynamics of Intensively Managed Loblolly Pine Stands in the Southern United States: A Synthesis of Seven Long-Term Experiments. Forest Ecology and Management, 192, 117-130. https://doi.org/10.1016/j.foreco.2004.01.007

Jose, S., Merritt, S., \& Ramsey, C. L. (2003). Growth, Nutrition, Photosynthesis and Transpiration Responses of Longleaf Pine Seedlings to Light, Water and Nitrogen. Forest Ecology and Management, 180, 335-344. https://doi.org/10.1016/S0378-1127(02)00583-2

Klute, A. (1986). Methods of Soil Analysis: Part 1-Physical and Mineralogical Methods (2nd ed.). Madison, WI: American Society of Agronomy, Inc. and Soil Science Society of America.

Knapp, B. O., Wang, G. G., \& Walker, J. L. (2008). Relating the Survival and Growth of Planted Longleaf Pine Seedlings to Microsite Conditions Altered by Site Preparation Treatments. Forest Ecology and Management, 255, 3768-3777. https://doi.org/10.1016/j.foreco.2008.03.013

Larsen, H. S., South, D. B., \& Boyer, J. M. (1986). Root Growth Potential, Seedling Morphology and Bud Dormancy Correlate with Survival of Loblolly Pine Seedlings Planted in December in Alabama. Tree Physiology, 1, 253-263.

https://doi.org/10.1093/treephys/1.3.253

Lincoln, M. C., Will, R. E., Morris, L. A., Carter, E. A., Markewitz, D., Britt, J. R. et al. (2007). Soil Change and Loblolly Pine (Pinus taeda) Seedling Growth Following Site Preparation Tillage in the Upper Coastal Plain of the Southeastern United States. Forest Ecology and Management, 242, 558-568. https://doi.org/10.1016/j.foreco.2007.01.069

Louisiana Department of Agriculture and Forestry (1997-2007). Pine Plantation Survival Report (Published Annually). Baton Rouge, LA: Louisiana Department of Agriculture and Forestry.

Margolis, H. A., \& Brand, D. G. (1990). An Ecophysiological Basis for Understanding Plantation Establishment. Canadian Journal of Forest Research, 20, 375-390.

https://doi.org/10.1139/x90-056 
Morris, L. A., Ludovici, K. H., Torreano, S. J., Carter, E. A., Lincoln, M. C., \& Will, R. E. (2006). An Approach for Using General Soil Physical Condition-Root Growth Relationship to Predict Seedling Growth Response to Site Preparation Tillage in Loblolly Pine Plantations. Forest Ecology and Management, 227, 169-177. https://doi.org/10.1016/j.foreco.2006.02.031

NOAA, National Oceanic and Atmospheric Administration, National Centers for Environmental Information (2008). National Climate Report-Annual 2008. https://www.ncdc.noaa.gov/sotc/national/200813

Nunez-Mir, G. C., Iannone, B. V., Curtis, K., \& Fei, S. (2015). Evaluating the Evolution of Forest Restoration Research in a Changing World: A "Big Literature" Review. New Forests, 46, 669-682. https://doi.org/10.1007/s11056-015-9503-7

Oliet, J. A., \& Douglass, F. J. (2012). Restoring Forests: Advances in Techniques and Theory. New Forests, 43, 535-541. https://doi.org/10.1007/s11056-012-9354-4

Paterson, J. (1997). Growing Environment and Container Type Influence Field Performance of Black Spruce Container Stock. New Forests, 13, 329-339. https://doi.org/10.1023/A:1006598611412

Pinto, J. R., Marshall, J. D., Dumroese, R. K., Davis, A. S., \& Cobos, D. R. (2011). Establishment and Growth of Container Seedlings for Reforestation: A Function of Stocktype and Edaphic Conditions. Forest Ecology and Management, 261, 1876-1884. https://doi.org/10.1016/j.foreco.2011.02.010

Puttonen, P. (1989). Criteria for Using Seedling Performance Potential Tests. New Forests, 3, 67-87. https://doi.org/10.1007/BF00128902

Radoglou, K., \& Raftoyannis, Y. (2002). The Impact of Storage, Desiccation and Planting Date on Seedling Quality and Survival of Woody Plant Species. Forestry, 75, 179-190. https://doi.org/10.1093/forestry/75.2.179

Schultz, R. P. (1999). Loblolly-The Pine for the Twenty-First Century. New Forests, 17, 71-88. https://doi.org/10.1023/A:1006533212151

South, D. B., Boyer, J. N., \& Bosch, L. (1985). Survival and Growth of Loblolly Pine as Influenced by Seedling Grade: 13-Year Results. Southern Journal of Applied Forestry, 9, 76-81.

South, D. B., Rakestraw, J. L., \& Lowerts, G. A. (2001b). Early Gains from Planting Large-Diameter Seedlings and Intensive Management Are Additive for Loblolly Pine. New Forests, 22, 97-110. https://doi.org/10.1023/A:1012097924355

South, D. B., Rose, R. W., \& McNabb, K. L. (2001a). Nursery and Site Preparation Interaction Research in the United States. New Forests, 22, 43-58. https://doi.org/10.1023/A:1012079014625

Thompson, B. E. (1985). Seedling Morphological Evaluation-What You Can Tell by Looking. In: M. L. Durvea (Ed.), Proceedings of Workshop on Evaluating Seedling Quality: Principles, Procedures, and Predictive Abilities of Major Tests (pp. 59-71). Corvallis, OR: Oregon State University, Forest Research Laboratory. 